\title{
Instalasi MX Linux Pada Virtualbox
}

Muhammad Ullil Fahri

muhammad.fahri001@binus.ac.id

https://ullilfahri.skb.ovh/

\section{Latar Belakang}

Jika anda mau belajar linux, jangan langsung instalasi ke komputer kalian. Lebih baik gunakan virtualbox. Hal ini dikarenakan agar anda tidak merasa bingung ketika melihat tampilan linux untuk pertama kali. Dengan menggunakan virtual box anda bisa melihat linux secara penuh tanpa harus melakukan install ulang pada komputer.

MX Linux hadir dengan lingkungan desktop XFCE sebagai standar. XFCE terkenal ringan, jadi ini adalah opsi yang bagus untuk pengembang [1]. pada tulisan ini berfokus pada MX linux, alasan pemilihan MX linux dikarenakan ringan dan sangat mampu ketika dilakukan instalasi dengan virtual box.

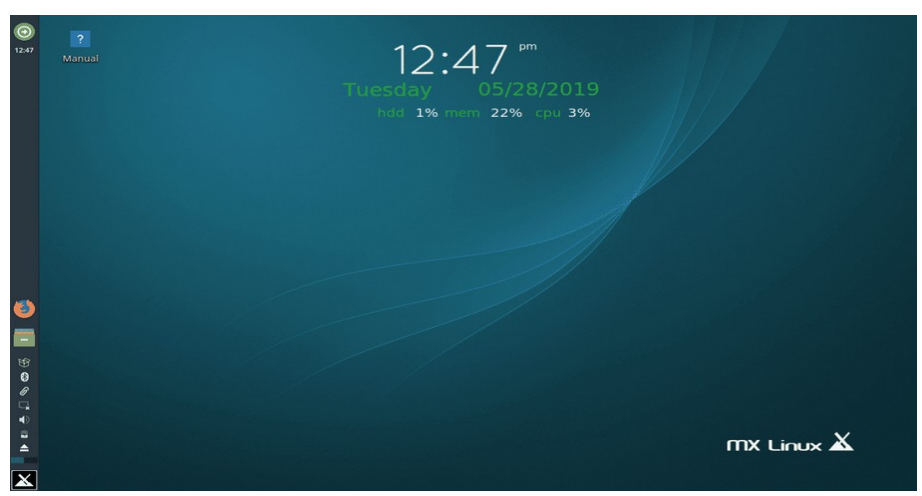

Gambar 1. Tampilan MX Linux

Pada gambar 1 merupakan tampilan dari MX linux. Dapat dilihat dari tampilan MX linux sangat sederhana sehingga mudah untuk melakukan pengoprasinya. Download MX linux pada tautan berikut ini https://mxlinux.org/download-links/ [2] . 
VirtualBox adalah aplikasi open source yang terkait dengan virtualisasi. Virtualisasi yang dimaksud adalah membuat mesin virtual PC yang dapat berjalan secara mandiri pada sistem operasi utama [3]. Dengan menggunakan virtual box maka kita bisa menjalankan sistem operasi diatas sistem operasi. Namun dalam hal ini perlu ada pahami juga penggunaan dari virtual box memakan memory RAM yang cukup besar. Berikut adalah kebutuhan minimal dari penggunaan virtualbox [4] :

1. Minimum 64 bit x86 Intel Core 2 Duo, prosesor AMD FX Dual Core atau yang setara

2. Kecepatan inti prosesor minimum $1,3 \mathrm{GHz}$ (disarankan $2 \mathrm{GHz}$ )

3. Minimal 2 GB RAM (disarankan 4 GB), ditambah jumlah RAM dari setiap sistem operasi virtual yang diinginkan

4. Setidaknya $300 \mathrm{MB}$ ruang kosong untuk menginstal VirtualBox, ditambah jumlah ruang hard disk untuk setiap mesin virtual yang diinginkan

5. VirtualBox bisa 32-bit and 64-bit.

Anda dapat melakukan download virtual box pada tautan berikut https://www.virtualbox.org/wiki/Downloads [5]. Pada tautan itu silahkan anda pilih di sesuaikan dengan sistem operasi yang anda gunakan.

Pada tulisan ini bertujuan menunjukkan kepada pembaca cara instalasi MX linux dengan menggunakan Virtual Box. Dengan harapan setelah anda menjalankan sistem operasi pada virtual box bisa langsung anda implementasikan pada komputer masing-masing. Tentunya dengan adanya virtual box dapat membuat kita melakukan testing terhadap sistem operasi.

\section{Pembahasan}

Berikut adalah langkah penggunaan virtual box dengan melakukan testing terhadap sistem operasi MX linux :

1. Download Virtual Box https://www.virtualbox.org/wiki/Downloads [5]

2. Download MX Linux https://mxlinux.org/download-links/ [2]

3. Silahkan Ikuti Langkah - Langkah Seperti pada gambar berikut 


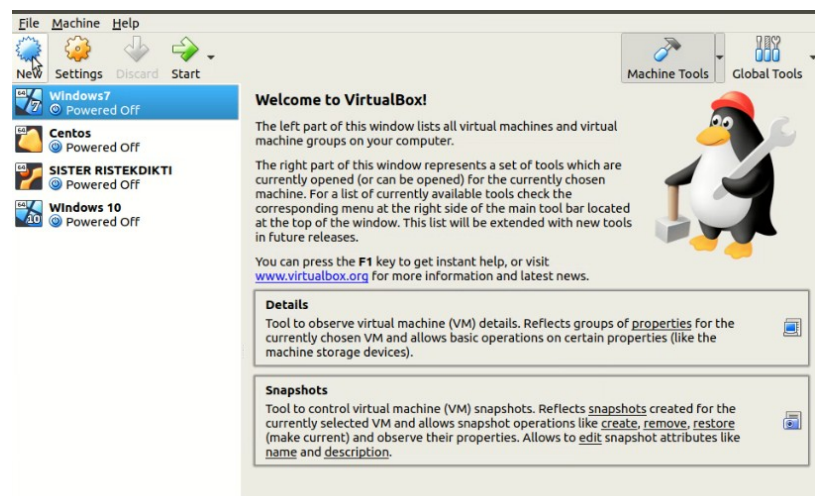

Gambar 2. Tampilan Virtualbox

Pada gambar 2 merupakan tampilan awal dari virtual box. Untuk memulai penggunaan dari virtual box silahkan anda pilih pada new.

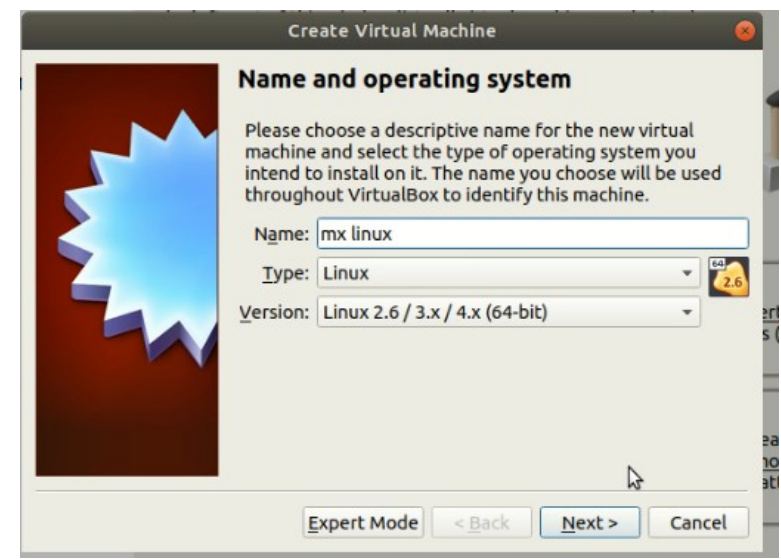

Gambar 3. Buat Sistem Operasi Virtual

Pada gambar 3 merupakan pembuat sistem operasi virtual yang akan diterapkan pada komputer anda. Sehubungan kita menggunakan sistem operasi tertinggi adalah MX linux silahkan diisi berdasarkan gambar 3. Setelah itu Pilih Next untuk melanjutkan ke langkah selanjutnya. 


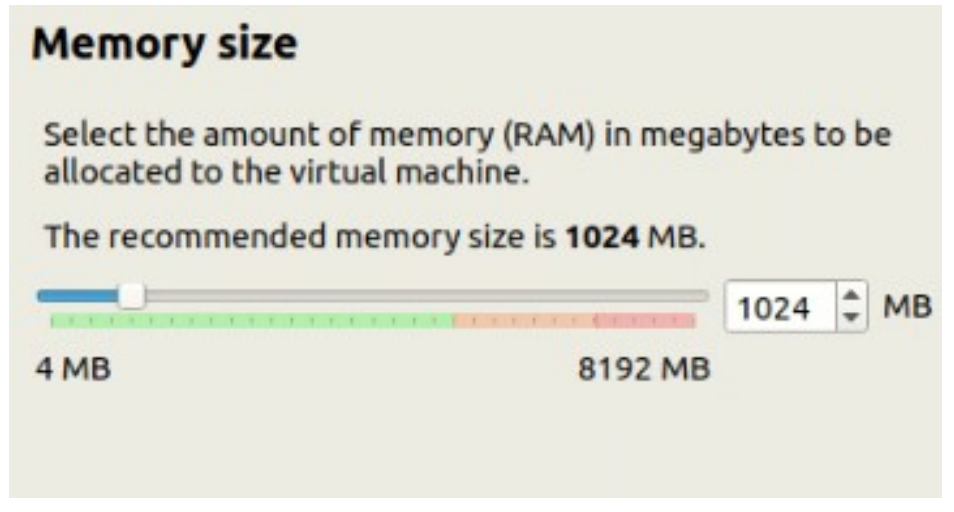

\section{Gambar 4. Penggunaan RAM}

Pada gambar 4 merupakan pemilihan RAM yang akan digunakan pada virtual box anda. MX linux tidak memerlukan RAM yang besar sehingga cukup digunakan 1 GB sudah cukup untuk menjalankan MX linux. Yang perlu anda ketahui adalah penggunaan RAM 1 GB berarti Ram komputer anda yang digunakan untuk Running virtual box adalah 1 GB. Contoh jika kamu memiliki komputer dengan RAM 4 GB , untuk menjalankan Virtual Box dengan RAM 1 GB maka Ram di komputer kamu tersisa 3 GB saja. Jika anda sudah benar dalam memilih penggunaan RAM , Silahkan Next terus.

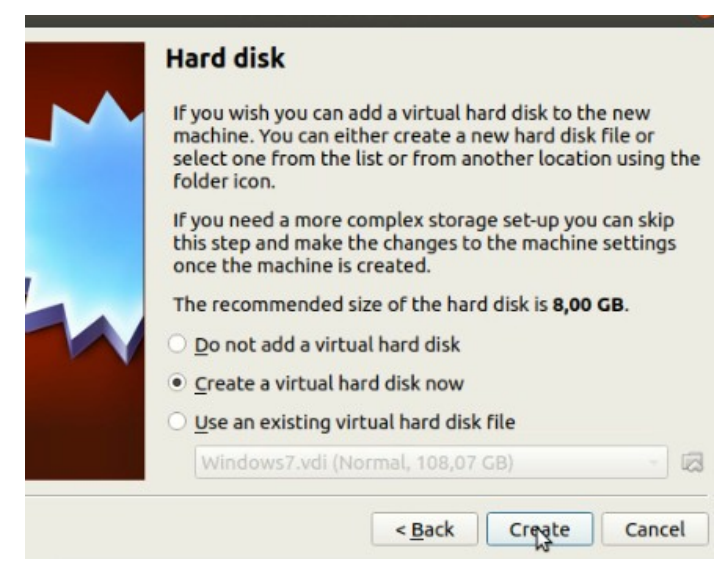

Gambar 4. Penggunaan Hardisk

Pada gambar 4 , Silahkan anda pilih Hardisk yang dialokasikan untuk virtual box. 


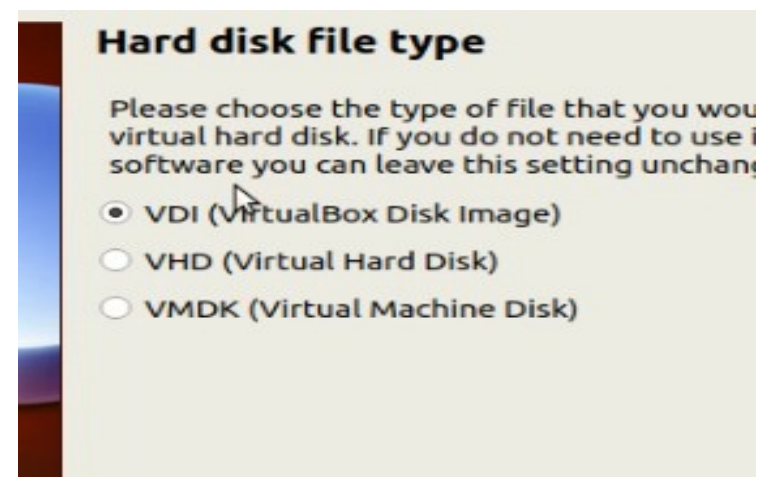

Gambar 5. Pemilihan Tipe Hardisk

Pada gambar 5 merupakan pemilihan tipe hardisk virtual yang digunakan. Agar mempermudah anda lebih baik tetap gunakan VDI ( Virtualbox Disk Image )

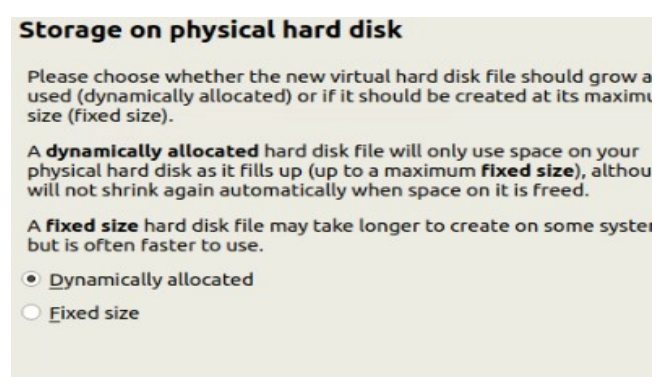

Gambar 6. Storage

Pada gambar 6 merupakan cara hardisk membaca data, jika anda memilih dynamically allocate maka hardisk yang anda siapkan akan diisi secara dinamis. Dalam hal ini penulis menyarankan anda memilih itu saja dibandingkan fixed Size

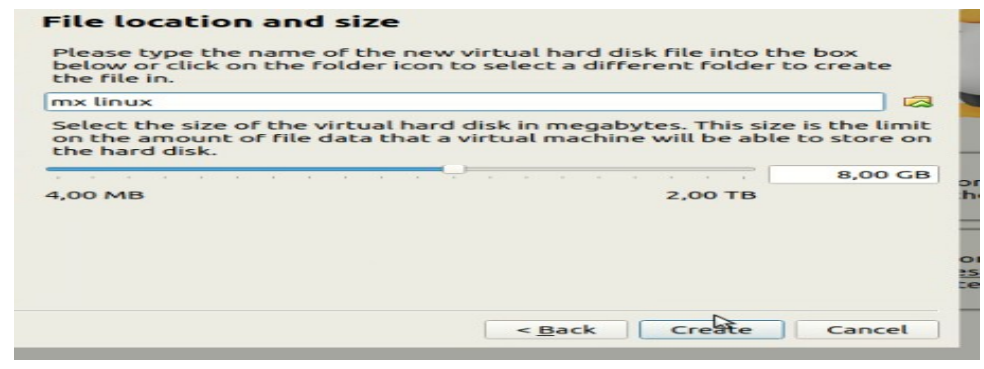

\section{Gambar 7. File Location}

Pada gambar 7 silahkan anda pilih lokasi yang akan digunakan untuk menyimpan hardisk 
virtual anda. Untuk ukuranya tidak perlu besar, dikarenakan kita melakukan instalasi dengan mx linux maka disk ukuranya cukup 8Gb. MX linux sudah bisa berjalan.

\section{Gambar 8. Virtual Sistem Operasi MX Linux}

Pada gambar 8, akan menampilkan kepada anda sistem operasi virtual telah berhasil dibuat.

Pada langkah selanjutnya, adalah cara melakukan pemilihan sistem operasi mx linux ( format iso ).

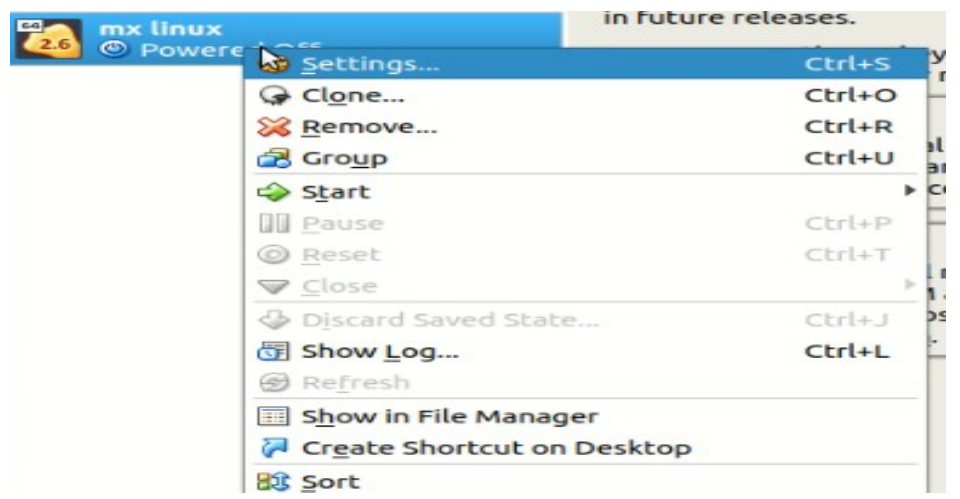

Gambar 9. Setting Virtualbox

Silahkan anda lakukan klik kanan pada mx linux virtual box. Pilih seting sesuai dengan gambar

9.

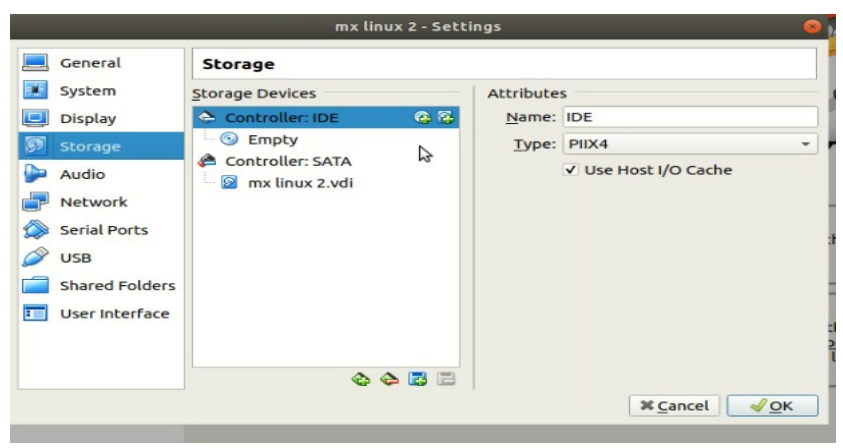

Gambar 10. Pengaturan Virtual Box

pada gambar 10 merupakan tampilan dari pengaturan virtualbox. Silahkan pilih menu storage 
untuk langkah selanjutnya.

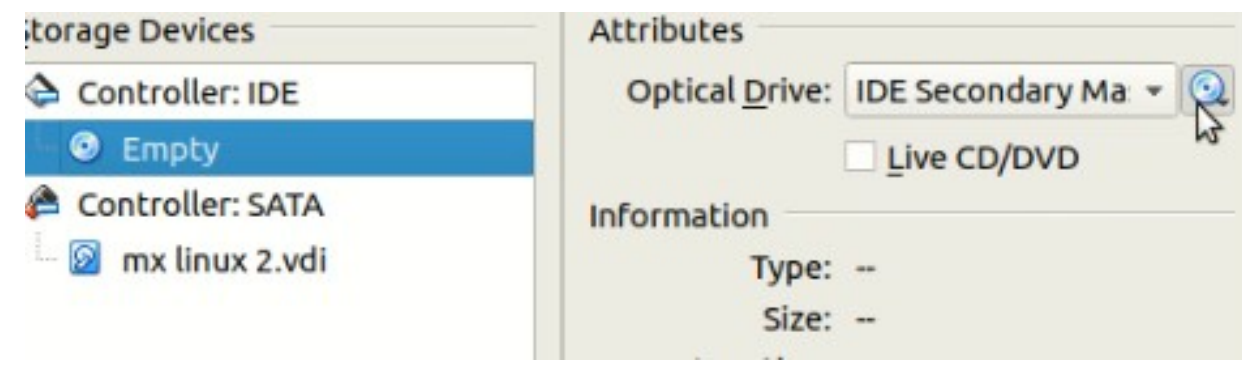

Gambar 11. Pemilihan Sistem Operasi MX Linux Iso

Silahkan anda pilih sesuai gambar 11. selanjutnya pilih empty baru kemudian anda arahkan pada optical drive. Klik untuk memilih sistem operasi mx linux yang berformat .iso

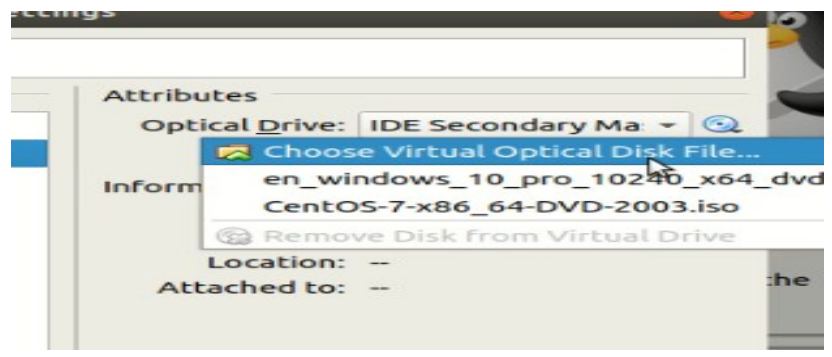

\section{Gambar 12. Pilih Iso File}

Pada gambar 12 silahkan pilih file iso yang sudah di download pada halaman mx linux https://mxlinux.org/download-links/ [2].

\section{MX-19.3 4 .iso}

Gambar 13. File Iso MX Linux 19.3

Pada gambar 13 menggunakan file iso MX linux dengan versi 19.3 


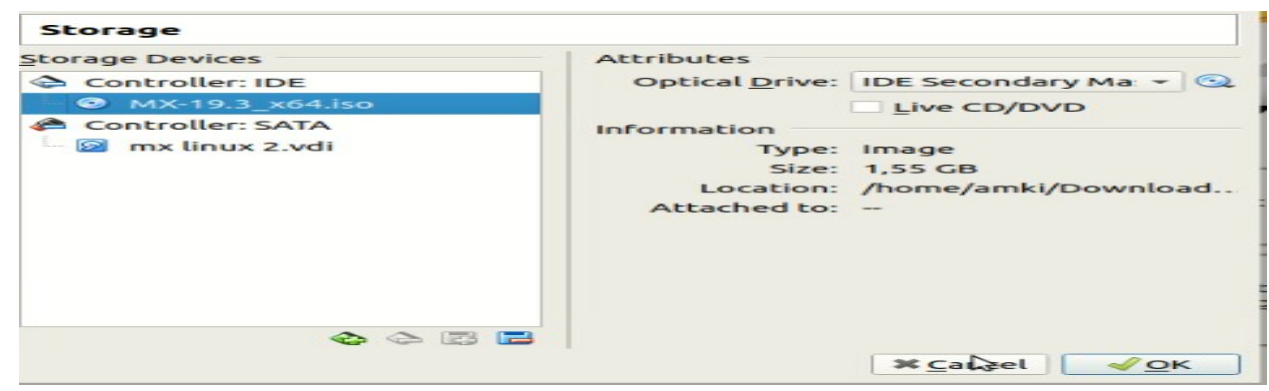

Gambar 14. Virtual Box Storage

Pada gambar 14 merupakan tampilan jika anda sudah benar melakukan pengaturan pada virtual box. Silahkan Pilih Ok untuk melanjutkan ke langkah selanjutnya

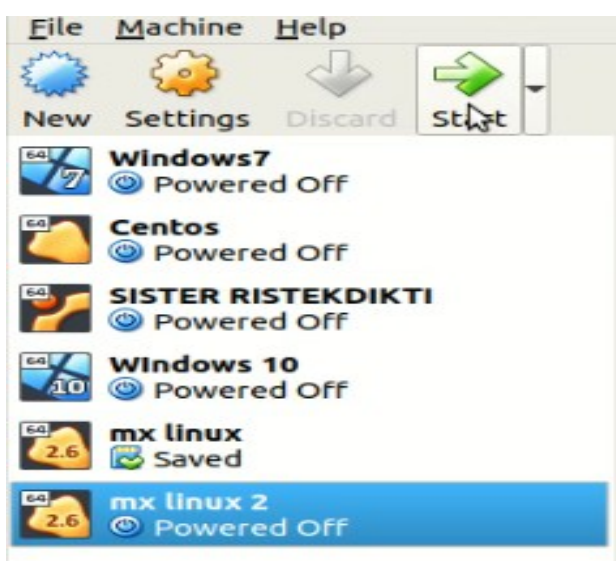

Gambar 15. Running Mx Linux

Pada gambar 15 Silahakan anda pilih Start untuk menjalankan Mx linux.

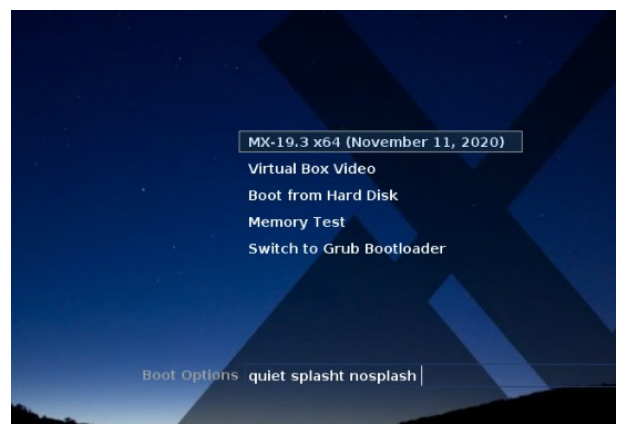

Gambar 16. Tampilan Awal Instalasi MX Linux 
Silahkan anda pilih yang paling atas pada gambar 16. Setelah anda pilih maka anda akan diarahkan lagi ke halaman instalasi dari linux mx

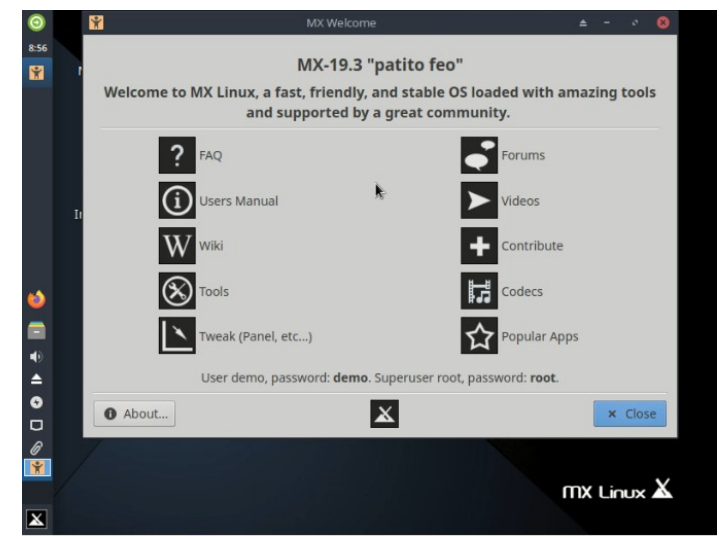

Gambar 17. Tampilan Start dari MX Linux

Saat pertama kali melakukan instalasi akan muncul seperti pada gambar di atas. Tampilan diatas merupakan tampilan dari welcome mx linux sebelum proses instalasi. Silahkan close saja.

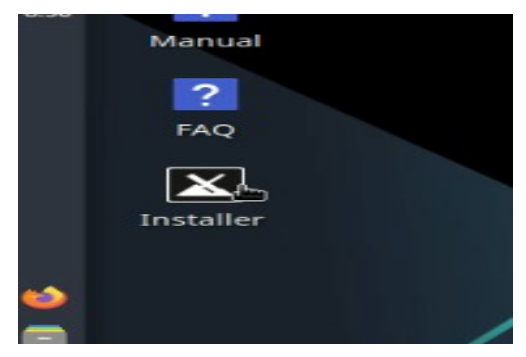

Gambar 18. Installer

Silahkan anda klik pada icon installer seperti pada gambar 18. selanjutnya anda akan diarahkan untuk proses instalasi ke sistem hardisk dari mx linux

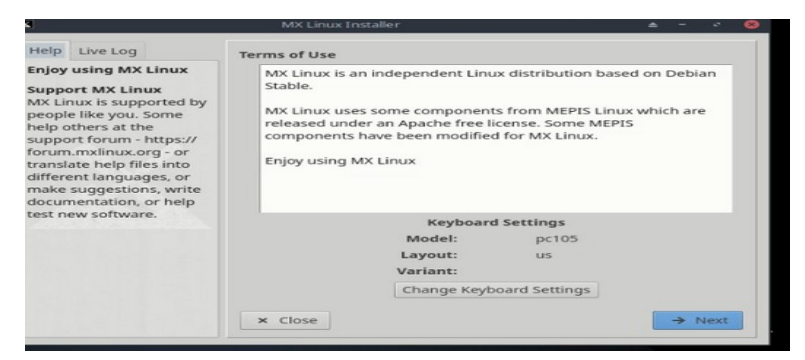

Gambar 19. Terms Of Use 
Silahkan anda next - next saja , pada proses gambar 19 merupakan sebuah persetujuan sebelum anda melakukan instalasi secara penuh pada sistem hardisk.

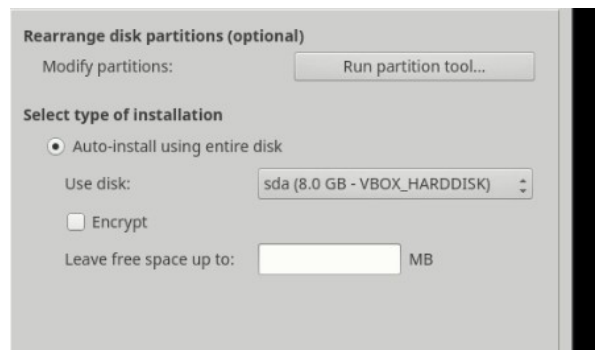

Gambar 20. Pemilihan Hardisk Dari Virtual Box

Pada gambar 20 merupakan memilih hardisk yang akan digunakan sebagai primary sistem dari mx linux anda. Pastikan settingan anda sudah sama seperti pada gambar 20. Jika sudah benar, selanjutnya pilih next

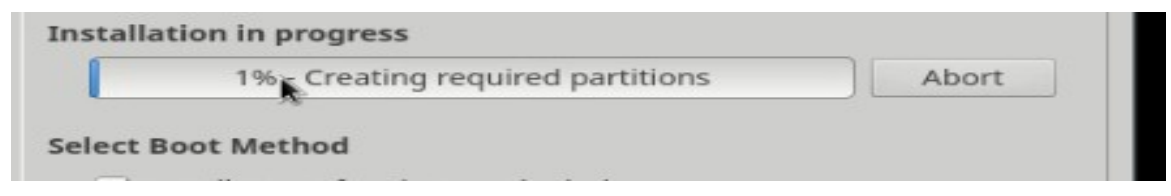

Gambar 21. Proses Instalasi MX Linux

Pada gambar 21 merupakan proses yang berjalan pada saat instalasi. Dimulai dari 1 \% hingga $100 \%$ anda bisa melakukan konfigurasi sambil proses berjalan. Untuk Konfigurasi lebih lanjut anda bisa next - next.

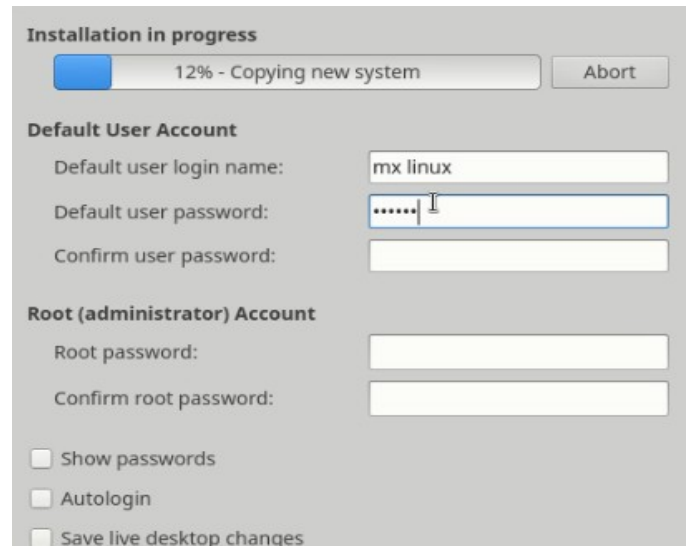

Gambar 22. Tampilan User Konfigurasi 
Jika tampil seperti gambar 22 merupakan proses penamaan dari komputer mx linux yang anda gunakan. Pastikan anda mengisi password dan jangan sampai lupa.

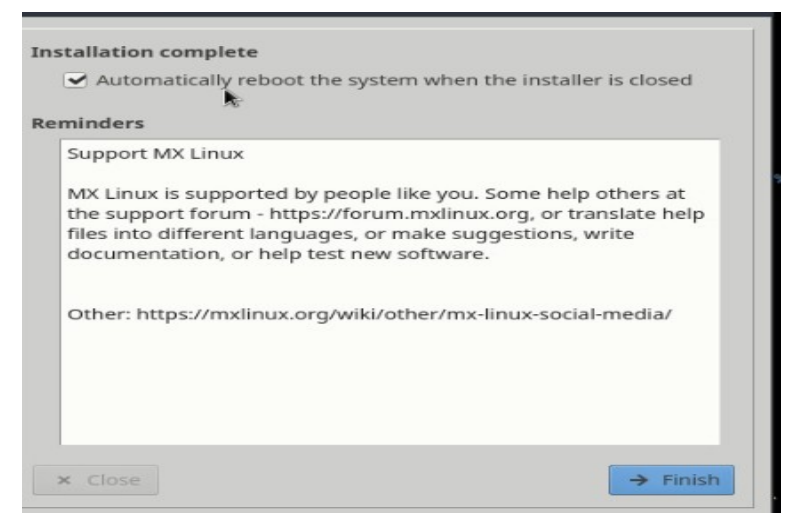

Gambar 23. Finalisasi Instalasi

Saat proses instalasi sudah selesai 100 \% maka akan tampil seperti pada gambar 23. silahkan anda klik finish maka secara otomatis sistem akan reboot ( system virtualbox )

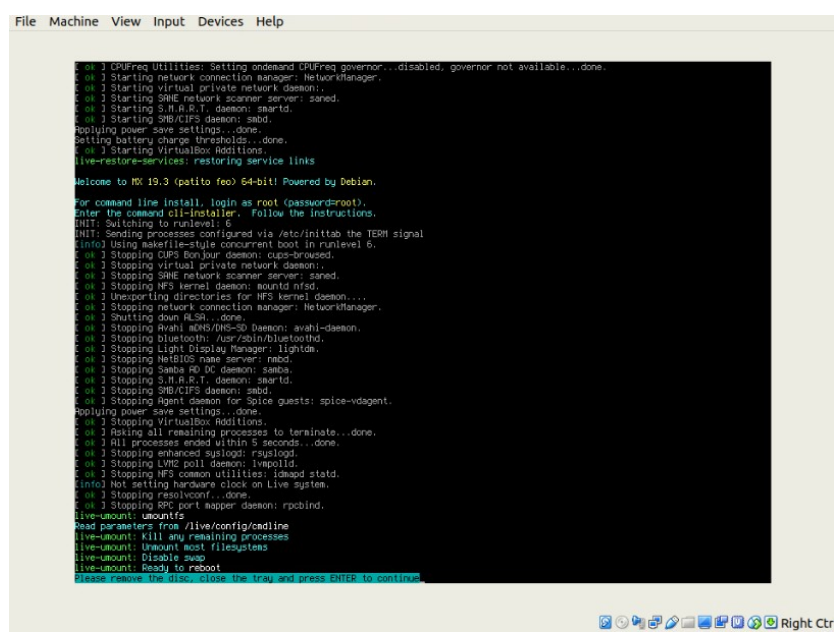

Gambar 24. Proses Reboot

Pada mx linux proses reboot akan tampil seperti pada gambar 24. dengan tampil seperti di atas maka proses instalasi berhasil dilakukan. 


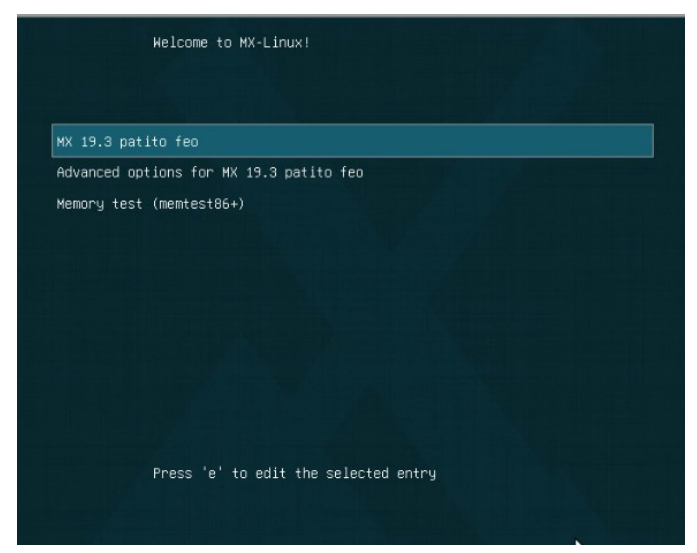

Gambar 25. Tampilan Booting Setelah Instalasi

Pada gambar 25 merupakan tampilan setelah melakukan reboot dari proses instalasi. Silahkan anda pilih yang paling atas Mx 19.3 patito Feo.

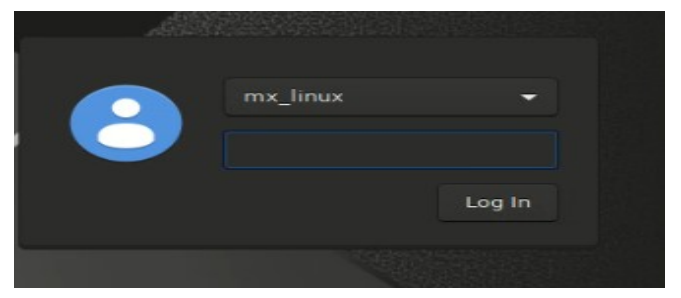

Gambar 26. Tampilan Login

Silahkan anda login sesuai pada gambar 26 dengan username password yang anda buat pada saat proses instalasi.

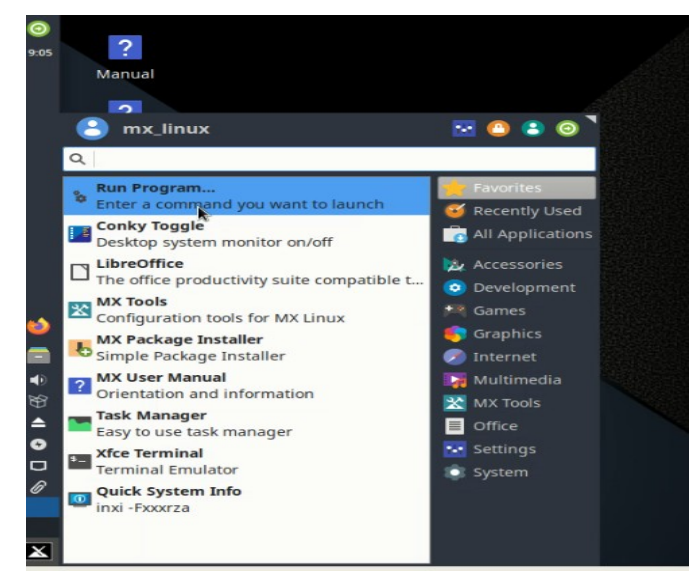

Gambar 27. Tampilan Menu Bar dari MX Linux 
Pada gambar 27 merupakan tampilan menu bar dari mx linux, terdapat ratusan software gratis yang dapat anda gunakan.

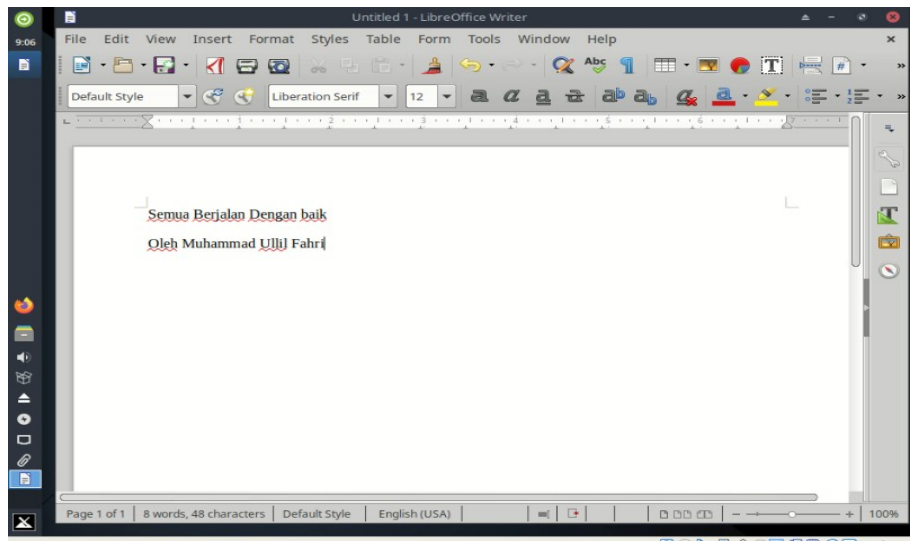

Gambar 28. Libre Office Word

Pada Gambar 28 merupakan tampilan dari libre office Word sebagai pengganti dari microsoft office. Aplikasi bersifat gratis sehingga anda tidak perlu lagi untuk pembelian software.

\section{Daftar Pustaka}

[1] Nooblasto, "Review Distro MX Linux : Distro Debian Populer dan Stabil.” https://www.nooblasto.com/review-mx-linux/\#! (accessed Nov. 15, 2020).

[2] Mx Linux, “Download Links.” https://mxlinux.org/download-links/.

[3] N. Huda, “Apa itu VirtualBox?,” 2020. https://jagongoding.com/others/apa-itu-virtual-box/.

[4] Teraa, "Menjalankan OS Dalam OS Dengan VMware dan VirtualBox.” https://teraa.net/vmware-virtualbox/.

[5] Virtualbox, “Download VirtualBox.” https://www.virtualbox.org/wiki/Downloads. 